\title{
5-Bromo-2'-deoxyuridine Incorporation into DNA in Hepatic VX2 Tumor-Bearing Rabbits ${ }^{1}$
}

\author{
James A. Knol, M.D., ${ }^{*}$ PhiliP L. Stetson, M.D., Ph.D., $\dagger$ John G. Wagner, Ph.D. $\ddagger$ Norma J. Johnson, $\dagger$ \\ Zhaomin Yang, M.D., $\uparrow$ Diane Prieskorn, $\uparrow$ Patricia Terrio, $\uparrow$ Conrad A. KnUtsen, $\dagger$ \\ and William D. Ensminger, M.D., PH.D. $\uparrow \S$ \\ Departments of *Surgery, †Pharmacology, and \$Internal Medicine, University of Michigan Medical Center; \\ $\ddagger$ School of Pharmacy, University of Michigan, Ann Arbor, Michigan
}

The halogenated pyrimidine 5-bromo-2'-deoxyuridine (BrdUrd) possesses both radiosensitizing and antimetabolite effects through its incorporation as a thymidine analog in replicating DNA. To evaluate the regional advantage for treatment of hepatic malignancy by hepatic arterial infusion, BrdUrd was infused into either the hepatic artery (HA) or a central vein (iv) in 26 rabbits with intrahepatic VX2 tumor. After a 24-hr constant rate infusion of 10,20 , or $40 \mathrm{mg} / \mathrm{kg} / 24 \mathrm{hr}$, the percentage BrdUrd incorporation into the DNA of bone marrow, duodenal mucosa, liver, and hepatic VX2 tumor was measured by gas chromatography/mass spectrometry methods. VX2 tumor BrdUrd incorporation was greater by $H A$ than by iv routes $(P<0.001)$. At doses of 10 and $20 \mathrm{mg} / \mathrm{kg} /$ day, $\mathrm{HA}$ to iv BrdUrd incorporation ratios for VX2 tumor significantly exceeded those for bone marrow and duodenum $(P<0.05)$. At appropriate dose rates, hepatic arterial administration of BrdUrd provides a regional advantage for DNA BrdUrd incorporation in the rabbit intrahepatic VX2 tumor. 1989 Academic Press, Inc.

\section{INTRODUCTION}

There has been a resurgence of interest recently in the halogenated pyrimidine 5-bromo-2'-deoxyuridine (BrdUrd) for potential use in cancer therapy. This agent localizes exclusively to DNA in the cell $[2,7]$ and acts by way of competition with thymidine for incorporation into replicating DNA by the replacement of thymine (Thy) with bromouracil (BrUra). In vitro, BrdUrd has been demonstrated to sensitize mammalian cells to the lethal effects of X-irradiation, ultraviolet light, and to radiomimetic alkylating agents $[4-6,9,10,14,15,19]$. Such sensitization has been shown in vitro to correlate in a nearly linear fashion with BrdUrd incorporation into DNA within the ranges of substitution achieved $[5,6,10$,

Presented at the Annual Meeting of the Association for Academic Surgery, Salt Lake City, Utah, November 16-19, 1988.

${ }^{1}$ Supported by NIH Grants CA33825 and CA42761.
19]. BrdUrd appears to also have direct cytotoxic effects that may be related to instability of DNA resulting from fraudulent base substitution. However, the mechanism of cytotoxicity remains poorly studied. Cell replication in vitro is only minimally affected after $\mathrm{BrUra}$ replacement of Thy. In some cell lines alteration in the synthesis of certain proteins has been observed after exposure to BrdUrd and has been demonstrated to be directly linked to the degree of BrdUrd incorporation into the cellular DNA $[20,21]$.

The goal of regional antineoplastic therapy is to achieve a high ratio of regional to systemic effect. Another consideration is the differential effect on tumor versus normal tissue in the treatment field. The use of pharmacologic agents for regional therapy requires attention to agentspecific pharmacokinetics and pharmacodynamics. The pharmacokinetics required for regional advantage are a high total body clearance and low regional exchange rate (blood flow) [1,3]. Extraction of drug by the target region results in less drug being delivered systemically and may contribute to regional advantage. Our pharmacokinetic studies of BrdUrd in the rabbit found a relatively high total body clearance of $163 \mathrm{ml} / \mathrm{min}$ and high hepatic extraction ratio of 0.74 at steady-state arterial levels of 0.9 $3.8 \mu M$ (unpublished data). A similar total body clearance was observed in humans by Russo et al. [13]. These pharmacokinetic data suggest that a selective advantage might occur for hepatic arterial delivery of BrdUrd in the treatment of hepatic malignancy.

The crucial issue, however, is that of pharmacodynamics, the study of the relationship of cellular response to exposure. We have used BrdUrd incorporation into DNA as a response parameter because extent of incorporation has been directly related to all cellular responses in the range of doses here utilized. In an earlier study of tissuespecific pharmacodynamics with systemic infusion of BrdUrd in the hepatic VX2 tumor-bearing rabbit, we found that response was nonlinear with dose [18]. After an initial rapid rise in the dose-response curve, a plateauing of the percentage of Thy replacement with BrUra with increasing plasma concentration of BrdUrd occurred such that an incorporation maximum $\left(I_{\max }\right)$ could be de- 
termined for each tissue. The $I_{\max }$ for bone marrow was significantly greater than that for VX2 tumor.

Our unpublished pharmacokinetic data for hepatic arterial BrdUrd infusion in the rabbit have shown a regional exposure advantage of 30 at low-dose rates which declines at higher dose rates. However, it was calculated that in the plateau portion of the BrdUrd incorporation doseresponse curve, because of the greater BrdUrd incorporation for bone marrow than for VX2 tumor, hepatic arterial infusion would achieve no BrdUrd incorporation advantage despite the exposure advantage. In other words, a high-dose hepatic arterial infusion would not necessarily be better than a low-dose infusion. Conversely, a lowdose arterial infusion might be superior because of a smaller difference between bone marrow and VX2 tumor percentage BrdUrd incorporation and a somewhat higher regional exposure advantage at low-dose rates.

On the basis of the forgoing reasoning, we proposed the hypothesis that regional advantage could be demonstrated for hepatic arterial BrdUrd infusion in rabbits with implanted hepatic VX2 tumor. Furthermore, we have attempted to delineate the dose range over which such advantage could be achieved.

\section{METHODS}

Study design. New Zealand white rabbits with VX2 tumor liver implants received $24 \mathrm{hr}$ continuous infusions of BrdUrd into the anterior vena cava (iv) or the hepatic artery (HA) at doses of 10 (iv, $n=4$; HA, $n=4$ ), 20 (iv, $n=4$; HA, $n=4$ ), or $40 \mathrm{mg} / \mathrm{kg}$ body wt $/ 24 \mathrm{hr}$ (iv, $n=6$; HA, $n=4)$. These doses were chosen on the basis of previous pharmacodynamic studies of iv BrdUrd at doses of $10-640 \mathrm{mg} / \mathrm{kg} / 24 \mathrm{hr}$ which suggested that an advantageous ratio of hepatic tumor to bone marrow BrdUrd incorporation was likely to occur at the lower doses [18]. Because DNA incorporation of BrdUrd is S-phase dependent, length of infusion for initial studies was selected as a minimum of one doubling time for VX2 tumor. In cell culture in our laboratory VX2 doubling time approximates $24 \mathrm{hr}$ (unpublished data) and was reported as 30 $\mathrm{hr}$ in a strain isolated by Yoneda et al. [23]. Doubling times for VX2 implanted in the rabbit have been calculated at approximately $12 \mathrm{hr}$ [22] to $24 \mathrm{hr}$ (our laboratory, unpublished).

The extent of substitution of Thy by BrUra in the DNA of normal liver, VX2 tumor, duodenal mucosa, and bone marrow was determined by gas chromatography/mass spectrometric methods [17]. Animal care conformed to both institutional and National Research Council's guidelines for the care and use of laboratory animals.

Statistical analysis employed multifactor ANOVA methods for an unbalanced design, and multiple comparisons were performed using the least significant difference method. Statistical significance was defined as $P \leqslant 0.05$.

Implantation of VX2 tumor. The VX2 carcinoma is an anaplastic squamous cell carcinoma originating from a virus-induced papilloma in the wild rabbit, but expressed as a carcinoma in the domestic rabbit [11]. Maintenance of the VX2 tumor utilized serial passage in the hindlimb of carrier rabbits at intervals of approximately 3 weeks. After sacrifice of the donor rabbit with iv injection of pentothal, the tumor was immediately stripped from surrounding connective tissue and rinsed in Eagle's MEM. Tumor was minced to $1-\mathrm{mm}^{3}$ fragments and to the resulting suspension was added purified collagenase to a concentration of $20 \mathrm{IU} / \mathrm{ml}$ suspension. After the mixture was stirred for $30 \mathrm{~min}$ at room temperature, an equal volume of Viokase $20 \%$ was added and the resultant mixture stirred $30 \mathrm{~min}$ at room temperature. The resulting suspension was seived through a Gelman filter holder without the filter to remove macroscopic tissue fragments. The cell suspension was centrifuged for $10 \mathrm{~min}$ at $2000 \mathrm{rpm}$ at room temperature. The pellet was resuspended in 1 to $2 \mathrm{ml}$ fresh Medium 199. On the basis of the estimate of viable cell number by microscopic examination using trypan blue staining, the cell concentration was adjusted to approximately $5 \times 10^{6} / \mathrm{ml}$ by the addition of Medium 199 . For carrying the tumor, the thigh muscle of New Zealand white rabbits was injected with $0.2 \mathrm{ml}\left(1 \times 10^{6}\right.$ cells $)$, which resulted in 1- to 2 -cm-diameter nodules in 3 weeks in $90 \%$ of innoculated animals.

New Zealand white rabbits weighing 2.5-3.5 kg were fasted for $18 \mathrm{hr}$, anesthetized with ketamine hydrochloride (44 mg/kg iv) and xylazine (10 mg/kg iv). Through a short midline incision caudad to the xyphoid, $0.2 \mathrm{ml}\left(1 \times 10^{6}\right.$ cells) of VX2 tumor suspension as prepared above was injected beneath the capsule in a single injection into the right and left hepatic lobes with a 25 -gauge needle. Gentle pressure was applied to the injection site immediately to avoid bleeding and suspension seepage. Dextran 70 (32\% solution, $50 \mathrm{ml}$ ) was placed in the abdominal cavity before closure to minimize adhesions. Ampicillin ( $250 \mathrm{mg}$ im bid) was administered for 2 days after the procedure. Isolated solid nodules $5-15 \mathrm{~mm}$ diameter developed by $12-16$ days after implantation.

Catheter placement. Catheters (silastic, 0.020 in i.d., 0.037 o.d.) for BrdUrd solution infusion were placed at 12-16 days after intrahepatic VX2 implantation and at $40-48 \mathrm{hr}$ prior to beginning drug infusion to allow recovery from anesthesia. Rabbits were allowed $a d$ lib access to food and water postanesthesia. Catheters were tunnelled subcutaneously to exit the skin of the upper back. Following placement of the catheter, rabbits were placed into a torso jacket which was fastened to a flexible, miniature swivel-tether system to allow continuous infusion through the catheter. The swivel-tether system allowed the rabbits unrestricted movement in the cage.

For iv infusion, a catheter was inserted into the right external jugular vein by cut down after administration of anesthesia as above. The tip of the catheter was advanced to the anterior vena cava.

For HA infusion, anesthesia was initiated as above, and the rabbits were orotracheally intubated and placed on a 
Harvard respirator. Adequate anesthesia was maintained with supplemental doses of ketamine hydrochloride. Through a midline incision, presence of tumor nodules in the liver was verified, and a catheter was inserted into the gastroduodenal artery with the tip advanced just distal to the bifurcation of common hepatic artery into proper hepatic and gastroduodenal arteries. The right gastric artery was ligated.

BrdUrd infusion. BrdUrd solutions were formulated as an alkaline ( $\mathrm{pH} 9.8), 0.10 \mathrm{M}$ carbonate/bicarbonate buffer solution, which allows concentrations up to 300 $\mathrm{mg} / \mathrm{ml}$ at body temperature and has less than $15 \%$ BrdUrd degradation over a 14 -day period at $37^{\circ} \mathrm{C}$. BrdUrd was administered continuously for $24 \mathrm{hr}$ iv or $\mathrm{HA}$ at specified concentrations at volumes of $2-3 \mathrm{ml} / \mathrm{hr}$ using a Harvard infusion pump. Steady-state plasma BrdUrd levels are achieved within $2 \mathrm{hr}$ at these doses (unpublished data). At 22,23 , and $24 \mathrm{hr}$ into the infusion, blood was drawn from an ear artery and heparinized, and the plasma stored at $-20^{\circ} \mathrm{C}$ until assay.

Sample preparation. Rabbits were euthanized with an overdose of pentothal iv immediately at the conclusion of the 24-hr infusion. The abdomen was opened and the liver removed, noting the presence of tumor. Normal liver tissue and tumor from each liver lobe were separately minced in lysing solution (10 $\mathrm{mM}$ Tris, $\mathrm{pH} 8.0,10 \mathrm{mM}$ EDTA, 0.6\% SDS) and gently homogenized in glass homogenizers. The slurries were brought to a minimum volume of $1 \mathrm{ml}$ with lysing solution. Bone marrow was removed from a femur, and mononuclear cells were isolated from the marrow by the Ficoll-Hypaque step gradient technique. Cells were washed with normal saline and lysed by final suspension in lysing solution. The duodenum was split lengthwise and rinsed with normal saline, after which mucosa was scraped off with a microscope slide and suspended in lysing solution. Collagenase solution $(0.10 \mathrm{ml}$, $10 \mathrm{mg}$ collagenase $/ \mathrm{ml}$ ) was mixed with each sample, after which the samples were vortexed and incubated at $37^{\circ} \mathrm{C}$ for $1 \mathrm{hr}$. Proteinase $\mathrm{K}$ solution $(0.10 \mathrm{ml}, 0.5 \mathrm{mg}$ proteinase $\mathrm{K} / \mathrm{ml}$ ) was added to each sample, and samples were vortexed and incubated 2 more $\mathrm{hr}$ at $37^{\circ} \mathrm{C}$. Aliquots of the resulting lysates were stored at $-20^{\circ} \mathrm{C}$ until assay.

Assay for BrdUrd. Plasma levels of BrdUrd were assayed by high-performance liquid chromatographic methods as previously described [16]. BrdIJrd incorporation into cellular DNA was determined by estimation of Thy and BrUra contents of cellular DNA using previously described methods $[12,17]$. Briefiy, DNA was precipitated and hydrolized to its bases, which were converted to trimethylsilyl derivatives. The Thy and BrUra base derivatives were quantitated using gas chromatography/mass spectrometric methods.

\section{RESULTS}

The percentages of BrUra replacement of Thy in the DNA of bone marrow, duodenal mucosa, normal liver, and intrahepatic VX2 tumor after $24 \mathrm{hr}$ continuous central venous (iv) infusion are displayed in Fig. 1. Significant increases in BrdUrd incorporation occurred for bone marrow, duodenal mucosa, and VX2 tumor, but not for normal liver over the dose range examined. At both dose rates greater than $10 \mathrm{mg} / \mathrm{kg} / 24 \mathrm{hr}$, bone marrow and VX2 tumor each demonstrated significantly greater BrdUrd incorporation than either duodenal mucosa or normal liver. At the $40 \mathrm{mg} / \mathrm{kg} / 24 \mathrm{hr}$ dose rate, there were significant differences in BrdUrd incorporation between each of the tissues examined.

Following $24 \mathrm{hr}$ hepatic arterial infusion of BrdUrd, incorporation of BrdUrd into VX2 tumor was significantly greater than that of liver and duodenum at all dose rates evaluated (Fig. 2). At the lower two doses VX2 tumor also exhibited a significantly greater BrdUrd incorporation than bone marrow, but at the $40 \mathrm{mg} / \mathrm{kg} / 24 \mathrm{hr}$ dose the bone marrow BrdUrd incorporation approached that of the VX2 tumor. Over this dose range, liver BrdUrd incorporation showed no significant rise. Bone marrow, VX2 tumor, and duodenal mucosa exhibited a significant increase in BrdUrd incorporation with increasing dose from 10 to $40 \mathrm{mg} / \mathrm{kg} / 24 \mathrm{hr}$, although there was no significant increase in incorporation in VX2 tumor between 20 and $40 \mathrm{mg} / \mathrm{kg} / 24 \mathrm{hr}$.

Compared to iv infusion over the 10 to $40 \mathrm{mg} / \mathrm{kg} / 24 \mathrm{hr}$ dose range, hepatic arterial infusion of BrdUrd resulted in a significantly increased BrdUrd incorporation in both intrahepatic VX2 tumor and in normal liver. Conversely, bone marrow exhibited a significantly greater BrdUrd incorporation when BrdUrd was administered systemically. There was no significant difference in duodenal mucosal BrdUrd incorporation by route of BrdUrd infusion.

To further evaluate hepatic regional perfusion of BrdUrd compared to systemic administration, ratios of BrdUrd incorporation into DNA after $H A$ versus iv infusion were calculated (Fig. 3). These ratios demonstrated a marked elevation of BrdUrd incorporation in the regionally perfused tissues (VX2 tumor and liver) compared

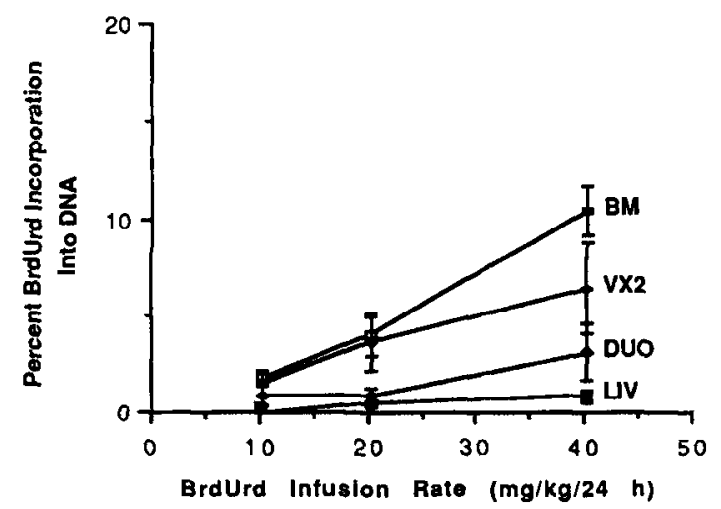

FIG. 1. Percentage of BrdUrd incorporation in the DNA of bone marrow (BM), hepatic VX2 tumor (VX2), duodenal mucosa (DUO), and normal liver tissue (LIV) after $24 \mathrm{hr}$ intravenous infusion of BrdUrd. 


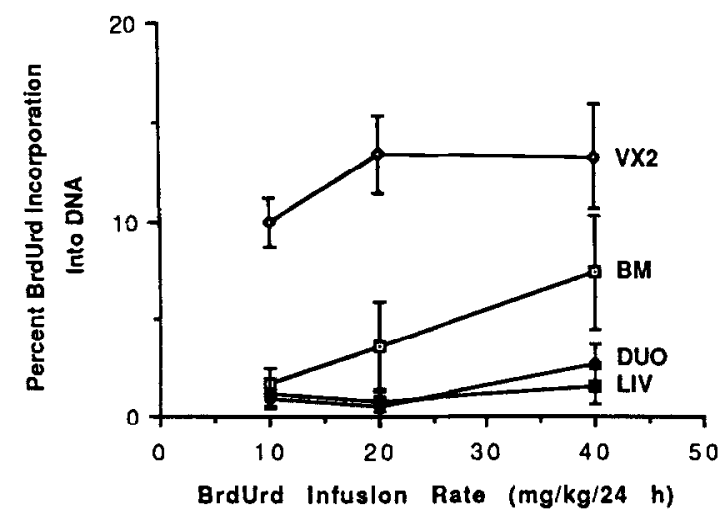

FIG. 2. Percentage of BrdUrd incorporation in the DNA of BM, VX2, DUO, and LIV after $24 \mathrm{hr}$ hepatic arterial infusion of BrdUrd.

to systemically exposed tissues at the lowest dose rate but a nearly complete loss of such advantage at the highest dose rate studied.

The ratios of BrdUrd incorporation in VX2 tumor to bone marrow may indicate the degree of potential systemic toxicity (Fig. 4). With HA infusion at the $10 \mathrm{mg} / \mathrm{kg} / 24$ hr dose the VX2 tumor to bone marrow BrdUrd incorporation ratio exceeded that at the higher arterial dose rates and is more than six times that of any systemic infusion dose rate.

\section{DISCUSSION}

Regional antineoplastic therapy is based on the principle of relatively high local exposure with simultaneous relatively low systemic exposure. Regional pharmacokinetics have been addressed by several authors and relate to regional versus systemic exposure to antineoplastic drugs $[1,3,8]$. However, drug effects at the cellular level may not display a linear relationship to exposure, and, therefore, the study of regional drug effects is essential to validate and optimize regional therapy. On the basis of the evidence that tissue DNA incorporation of BrdUrd is related in a direct fashion to BrdUrd tissue effects [5,

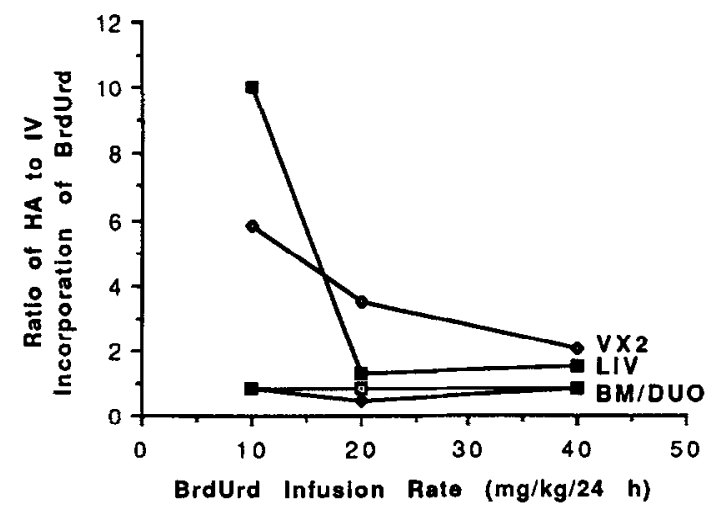

FIG. 3. Ratio of percentage BrdUrd incorporation into DNA after hepatic arterial (HA) $24 \mathrm{hr}$ infusion of BrdUrd and after intravenous (IV) infusion for VX2, LIV, BM, and DUO.

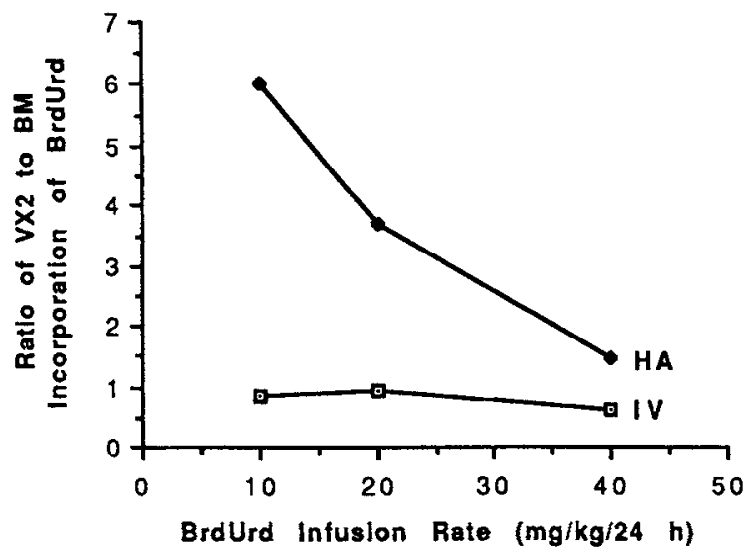

FIG. 4. Ratio of percentage BrdUrd incorporation into DNA in VX2 to that in the BM for HA and IV routes of infusion of BrdUrd for $24 \mathrm{hr}$.

$6,10,19]$, we have investigated here BrdUrd incorporation into tissues pertinent to intraarterial regional hepatic therapy, including those tissues likely to cause systemic toxicity, and have demonstrated that at appropriate dose rates in this particular hepatic tumor model the pharmacodynamics of regional hepatic therapy are advantageous.

The results of this investigation demonstrate that for 24-hr infusions regional advantage decreases with increasing dose rate over the range studied and suggest that no regional advantage will be present at dose rates greater than $40 \mathrm{mg} / \mathrm{kg} / 24 \mathrm{hr}$. These results confirm predictions made in a previous study that hepatic regional advantage should be possible at low infusion rates of BrdUrd [18]. In that study of systemic BrdUrd pharmacodynamics with 24-hr infusions, tissue BrdUrd incorporations were not linear with dose but began to plateau as higher dose infusions were administered. Because BrdUrd incorporations in bone marrow were greater than those seen in VX2 tumor, it was theorized that only at low-dose levels would the increased exposure provided by regional infusion not be counterbalanced by the greater BrdUrd incorporation in bone marrow.

The results obtained for tissue BrdUrd incorporation must be interpreted with caution because of the limited time of infusion. Cell kinetics in the tissues studied here are pertinent to the potential effects and toxicity of prolonged infusions. The rate of cell division in a particular tissue is a major determinant of the rate of BrdUrd incorporation. BrdUrd incorporation rate will reflect DNA replication rate, but it is likely that BrdUrd incorporation is also modified by tissue-specific factors. For the tissues in this study, BrdUrd labeling indices have been obtained by immunohistochemical methods using a BrdUrd-specific monoclonal antibody [18]. BrdUrd labeling indices, which reflect the proportion of actively dividing cells in a tissue sample, are high for bone marrow, duodenal crypt epithelium, and VX2 tumor, but are low for normal liver. Correspondingly, we observed a relatively higher BrdUrd 
incorporation in bone marrow, VX2, and duodenum compared to normal liver, seen best with iv infusion at 40 $\mathrm{mg} / \mathrm{kg} / 24 \mathrm{hr}$.

Another major determinant of BrdUrd replacement in cellular DNA within tissues is cell half-life, a factor not addressed by the methods utilized here. Both bone marrow and duodenal mucosa follow the pattern of stem cells producing a population of cells which mature over 3-5 days and then exit the tissue. With steady-state exposure, bone marrow and duodenal mucosa would be expected to increase total tissue BrdUrd incorporation rapidly for approximately 5 days and then to plateau. Liver cells do not exit the tissue compartment in large numbers over a period of even weeks so that liver tissue would theoretically show a very gradual but prolonged rise in Brd incorporation with continuous steady-state exposure. Solid tumor cellular behavior varies considerably and remains somewhat obscure, but characteristically there is rapid cellular division in the outer layers with progressively slower division toward the relatively ischemic central portion. Loss of total cell numbers is presumably small except by ischemic cell death. With steady-state exposure to BrdUrd, tumor would likely exhibit a somewhat rapid rate of BrdUrd incorporation, then tapering to a more gradual but continuing increase. The assumptions underlying the foregoing predictions of tissue BrdUrd incorporation are that the reparative cellular processes which remove BrUra from DNA play a minor role, and that BrdUrd incorporation does not by itself lead to major cytotoxic effects.

In summary, although many aspects of hepatic arterial BrdUrd pharmacodynamics remain to be delineated, we have demonstrated that regional advantage can be achieved with hepatic arterial BrdUrd infusion and have defined the appropriate dose range. Because of the nonlinear dose-response curve for BrdUrd, and because bone marrow, a common source of dose-limiting toxicity, exhibits the greatest BrdUrd incorporation of the tissues examined, a high-dose infusion is without regional advantage. We plan to use this hepatic VX2 tumor-bearing rabbit model to assay for maintenance or perhaps even an increase in regional advantage with prolonged BrdUrd infusions. Favorable results should be applicable to clinical use of BrdUrd infusions in hepatic regional antineoplastic therapy.

\section{REFERENCES}

1. Chen, H-S. G., and Gross, J. F. Intra-arterial infusion of anticancer drugs: Theoretic aspects of drug delivery and review of responses. Cancer Treat. Rep. 64: 31, 1980.

2. Cheong, L., Rich, M. A., and Eidinoff, M. L. Introduction of the 5 -halogenated uracil moiety into deoxyribonucleic acid of mammalian cells in culture. $J$. Biol Chem. 235: $1441,1960$.

3. Collins, J. M. Pharmacologic rationale for regional drug delivery. J. Clin. Oncol. 2: 498, 1984.

4. Delihas, N., Rich, M. A., and Eidinoff, M. L. Radiosensitization of a mammalian cell line with 5-bromodeoxyuridine. Radiat. Res. $17: 479,1962$.
5. Dewey, W. D., and Humphrey, R. M. Increase in radiosensitivity to ionizing radiation related to replacement of thymidine in mammalian cells with 5-bromodeoxyuridine. Radiat. Res. 26: 538, 1965.

6. Djordjevic, B., and Szybalski, W. Genetics of human cell lines. III. Incorporation of 5-bromo- and 5-iododeoxyuridine into the deoxyribonucleic acid of human cells and its effect on radiation sensitivity. J. Exp. Med. 112: 509, 1960.

7. Eidinoff, M. L., Cheong, L., and Rich, M. A. Incorporation of unnatural pyrimidine bases into deoxyribonucleic acid of mammalian cells. Science 129: 1550, 1959.

8. Ensminger, W. D., and Gyves, J. W. Clinical pharmacology of hepatic arterial chemotherapy. Semin. Oncol. 10: 176, 1983.

9. Erikson, R. L., and Szybalski, W. Molecular radiobiology of human cell lines. I. Comparative sensitivity to X-rays and ultraviolet light of cells containing halogen-substituted DNA. Biochem. Biophys. Res. Commun. 4: 258, 1961.

10. Erikson, R. L., and Szybalski, W. Molecular radiobiology of human cell lines. V. Comparative radiosensitizing properties of 5 -halodeoxycytidines and 5-halodeoxyuridines. Radiat. Res. 20: 252, 1963.

11. Kidd, J. G., and Rouse, P. A. A transplantable rabbit carcinoma originating in a virus-induced papilloma and containing the virus in masked or altered form. J. Exp. Med. 71: 813, 1940.

12. Maybaum, J., Kott, M. G., Johnson, N. K., Ensminger, W. D., and Stetson, P. L. Analysis of bromodeoxyuridine incorporation into DNA: Comparison of gas chromatographic/mass spectrometric, $\mathrm{CsCl}$ gradient sedimentation and specific radioactivity methods. Anal. Biochem. 161: 164, 1987.

13. Russo, A., Gianni, L., Kinsella, T. J., et al. Pharmacological evaluation of intravenous delivery of 5 -bromodeoxyuridine to patients with brain tumors. Cancer Res. 44: 1702, 1984.

14. Schindler, F., Ramseier, L., and Grieder, A. Increased sensitivity of mammalian cell cultures to radiomimetic alkylating agents following incorporation of 5-bromodeoxyuridine into cellular DNA. Biochem. Pharmacol. 15: 2013, 1966.

15. Shipley, W. U., Elkind, M. M., and Prather, W. W. Potentiation of X-ray killing by 5-bromodeoxyuridine in Chinese hamster cells: a reduction in capacity for sublethal damage accumulation. Radiat. Res. 47: 437, 1971.

16. Stetson, P. L., Shukla, U. A., Amin, P. R., and Ensminger, W. D. High-performance liquid chromatographic method for the determination of bromodeoxyuridine and its major metabolite, bromouracil, in biological fluids. J. Chromatogr. 341: 217, 1985.

17. Stetson, P. L., Maybaum, J., Shukla, U. A., and Ensminger, W. D. The simultaneous determination of thymine and 5-bromouracil in DNA hydrolysates using GC/MS-SIM. J. Chromatogr. 375: 1, 1986.

18. Stetson, P. L., Maybaum, J., Wagner, J. G., Averill, D. R., Wollner, I. S., Knol, J. A., Johnson, N. J., Yang, Z., Preiskorn, D., Smith, P., Knutsen, C. A., and Ensminger, W. D. Tissue-specific pharmacodynamics of 5-bromo-2'-deoxyuridine incorporation into DNA in VX2 tumor-bearing rabbits. Cancer Res. 48: 6900, 1988.

19. Szybalski, S. X-ray sensitization by halopyrimidines. Cancer Chemother. Rep. 58: 539, 1974.

20. Walther, B. T., Pictet, R. L., David, J. D., and Rutter, W. J. On the mechanism of 5 -bromodeoxyuridine inhibition of exocrine pancreas differentiation. $J$. Biol. Chem. 249: $1953,1974$.

21. Wishnow, R. M., Feist, P., and Glowalla, M. B. The effect of 5bromodeoxyuridine on steroidogenesis in mouse adrenal tumor cells. Arch. Biochem. Biophys. 161: 275, 1974.

22. Yamashita, Y., Takahashi, M., Fukushima, S., Nishida, M., and Nakano, M. Experimental study of hepatic artery embolization: Evaluation of various embolic materials. Radiat. Med. 5: 75, 1987.

23. Yoneda, T., Kitamura, M., Ogawa, R., Aya, S., and Sakuda, M. Control of $\mathrm{VX}_{2}$ carcinoma cell growth in culture by calcium, calmodulin, and prostaglandins. Cancer Res. 45: 398, 1985. 